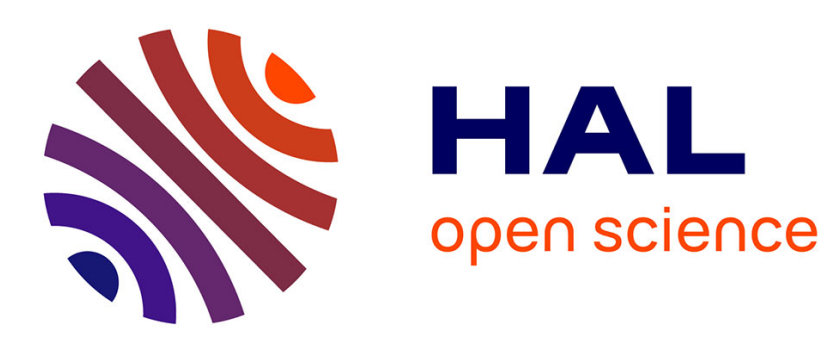

\title{
Radiolysis of pyridine in solid water
}

Prudence C. J. Ada Bibang, Aditya N Agnihotri, Philippe Boduch, Alicja Domaracka, Zuzana Kanuchova, Hermann Rothard

\section{To cite this version:}

Prudence C. J. Ada Bibang, Aditya N Agnihotri, Philippe Boduch, Alicja Domaracka, Zuzana Kanuchova, et al.. Radiolysis of pyridine in solid water. The European Physical Journal D: Atomic, molecular, optical and plasma physics, 2021, 75 (2), pp.57. 10.1140/epjd/s10053-021-00058-y . hal03143008

\section{HAL Id: hal-03143008 https://hal.science/hal-03143008}

Submitted on 16 Feb 2021

HAL is a multi-disciplinary open access archive for the deposit and dissemination of scientific research documents, whether they are published or not. The documents may come from teaching and research institutions in France or abroad, or from public or private research centers.
L'archive ouverte pluridisciplinaire HAL, est destinée au dépôt et à la diffusion de documents scientifiques de niveau recherche, publiés ou non, émanant des établissements d'enseignement et de recherche français ou étrangers, des laboratoires publics ou privés. 


\title{
Radiolysis of pyridine in solid water
}

\author{
Prudence C. J. Ada Bibang ${ }^{1}$, Aditya N. Agnihotri ${ }^{1, a}$, Philippe Boduch ${ }^{1}$, \\ Alicja Domaracka ${ }^{1, *}$, Zuzana Kanuchova $^{2}$, Hermann Rothard $^{1}$ \\ ${ }^{1}$ Centre de Recherche sur les Ions, les Matériaux et la Photonique,
} Normandie Univ, ENSICAEN, UNICAEN, CEA, CNRS, CIMAP, 14000 Caen, France

${ }^{2}$ Astronomical Institute of the Slovak Academy of Science, 05960 Tatranska Lomnica, Slovak Republic

${ }^{a}$ now at: Indian Institute of Technology Delhi, India

*alicja.domaracka@ganil.fr

\begin{abstract}
We irradiated the complex organic molecule pyridine and mixtures of pyridine and water in solid phase (thin icy films) at $12 \mathrm{~K}$ at different beam lines of the GANIL facility (ARIBE: 90 $\mathrm{keV} \mathrm{O}{ }^{6+}$, SME: $650 \mathrm{MeV} \mathrm{Zn}^{26+}$ ). The destruction of the initial molecule and the appearance of radiolytic products were followed by in-situ infrared absorption spectroscopy as a function of the projectile fluence with the CASIMIR experimental set-up of CIMAP. We measured the destruction cross section as a function of pyridine concentration. A clear dependence on the percentage of pyridine in $\mathrm{H}_{2} \mathrm{O}$ was found: the destruction cross sections are significantly higher for small concentration, i.e. pure pyridine is more radioresistant than pyridine diluted in water ice at $12 \mathrm{~K}$. Thus, the presence of water environment significantly modifies the radiation resistance of the initial complex organic molecules: it enhances radiosensitivity and destruction of pyridine, with implications for radiobiology and astrochemistry.
\end{abstract}




\section{Introduction}

Complex organic molecules (COMs) can be formed in space by interactions between ionizing radiation and small molecules condensed as thin icy layers on dust grains [1,2]. Micrometeorites deliver organic matter from space to Earth and thus may have contributed to the emergence of life [3]. COMs were found in the Murchison meteorite (nucleobases] [4], in comets (amino acid) [5] and have been detected by ESA's ROSETTA mission on comet 67P/ChuryumovGerasimenko [6-7]. Once formed in space, COMs are also exposed to a complex ionizing radiation field (UV, $\mathrm{x}$-rays, electrons, cosmic ray ions). The question arises thus, how long can they survive in space? It is therefore necessary to study their radiation resistance in order to determine the survival times of complex molecules.

In the following, we present laboratory studies performed at different ion beamlines of GANIL facility (Caen/France). The effects of heavy ion irradiation on ices of astrophysical interest have been studied within our collaborations since about ten years [8-9]. Radiolysis of numerous simple ices and mixtures of up to four simple molecules were studied. Irradiation not only leads to fragmentation of initial molecules, but also to synthesis of COMs such as glycine. We also studied to what extend implanted projectiles contribute to the synthesis of molecules. Furthermore, radiation resistance of COMs such as nucleobases and amino acids was investigated [10]. In the work presented here, we focus on the COM pyridine with the chemical formula $\mathrm{C}_{5} \mathrm{H}_{5} \mathrm{~N}$. The structure of pyridine closely resembles that of benzene with one $\mathrm{C}-\mathrm{H}$ unit substituted with a nitrogen atom. It has been proposed that small nitrogen containing molecules, such as pyridine, can play a role in the first steps leading to formation of large nitrogen containing (polycyclic) aromatic hydrocarbons (PNAH) and of prebiotic molecules such as nucleobases [11].

In Sec. 2, briefly, the experimental method is described. In Sec. 3, we show results obtained by FTIR spectroscopy of icy films of pure pyridine and pyridine-water mixtures at low temperatures (around $12 \mathrm{~K}$ ) irradiated by different heavy ions (ARIBE and SME), which are discussed in Sec. 4 in the framework of astrophysical and biological implications. At short Outlook is drawn in Sec. 5. 


\section{Experimental procedures}

For this experiment at GANIL (Grand Accélérateur National d'Ions Lourds; Caen, France), we have used two different ion beam lines: the low energy line ARIBE delivered an ${ }^{\mathbf{1 6}^{6}} \mathbf{O}^{\mathbf{6}+}$ beam at $90 \mathrm{keV}$, and the medium energy SME beam line ${ }^{70} \mathrm{Zn}^{26+}$ at $650 \mathrm{MeV}$. The CASIMIR set-up (Chambre d'Analyse par Spectroscopy Infrarouge des Molécules IRradiées), dedicated to FTIR spectroscopy with low temperature samples can be mounted on both of these beam lines. This set-up allows to follow the evolution of structure (compact, porous, amorph, crystalline) and chemical composition of ices during irradiation with ionic projectiles by performing infrared absorption measurements. CASIMIR is composed of $: i$ ) a high vacuum chamber (base pressure at room temperature of the order of $5 \times 10^{-7} \mathrm{mbar}, 2 \times 10^{-8}$ mbar with the target cooling system working) connected to the accelerator beamlines; ii) a closed-cycle helium cryostat connected to a sample holder for IR transparent windows on which the thin icy films are prepared. A heating system allows to adjust the substrate temperature from $12 \mathrm{~K}$ to $300 \mathrm{~K}$; iii) a Nicolet Magna 550 FTIR spectrometer in the $4000-500 \mathrm{~cm}^{-1}$ range operated with spectral resolution of $1 \mathrm{~cm}^{-1}$; iv) a gas mixing ramp where it is possible to prepare a mixtures of gases or vapors to be injected onto the cold substrate in the main chamber. The ion beam impinges perpendicularly on the target. To assure homogenous irradiation of icy samples, the ion beam is swept uniformly over the whole target surface. The irradiated area is of $10 \mathbf{~ m m}$ diameter. A detailed description of experimental set up and sweeping device for high and low-energy beam lines can be found elsewhere [12,13].

The thin ice film samples have been obtained by condensation of a room temperature vapor of pure pyridine (Sigma-Aldrich, purity $\geq 99 \%$ ) and mixtures of pyridine and water vapor onto the pre-cooled $\mathrm{ZnSe}$ substrate at $12 \mathrm{~K}$. Pyridine and deionised water were subjected to multiple freeze-pump-thaw-cycles under vacuum to remove dissolved gases. The experimental protocol includes the following steps: i) take a background FTIR spectrum; ii) prepare the pure pyridine vapor or a mixture of pyridine and water vapor at a certain pyridine percentage; iii) prepare the thin layers by condensation of the vapor through a needle onto the $\mathrm{ZnSe}$ window; iv) take a FTIR spectra, v) irradiate the samples with a certain projectile fluence; vi) repeat steps iv) and v) until the desired final projectile fluence is reached; vii) analyze the spectra taken before and after irradiation by identifying the observed peaks and calculating their area; viii) trace the evolution of the peak areas as a function of the projectile fluence and calculate the 
destruction section from the observed exponential decrease.

The molecular column density of a sample was determined from the relation between optical depth $\tau_{v}=\ln \left(\mathrm{I}_{0} / \mathrm{I}\right)$ and the integrated band strength $\mathrm{A}$ in $\mathrm{cm}$ molecules ${ }^{-1}$. In this expression, $\mathrm{I}$ and $I_{0}$ are the intensity of light at a specific frequency before and after passing through a sample, respectively, and the absorbance measured by the FTIR spectrometer is $A_{b s}=\log \left(I_{0} / I\right)$. The deposited ice column density can be calculated from

$$
\mathrm{N}=\frac{1}{A} \int \tau(v) \mathrm{d} v=\frac{2.3}{A} \int \mathrm{Abs}_{v} \mathrm{~d} v
$$

where $\mathrm{N}$ is the column density in molecules $\mathrm{cm}^{-2}, \mathrm{Abs}_{v}=\ln \left(\mathrm{I}_{0} / \mathrm{I}\right) / \ln (10)=\tau_{v} / 2.3$. The effective initial composition was obtained using the pyridine band at $711 \mathrm{~cm}^{-1}$ and the water band at 3250 $\mathrm{cm}^{-1}$ as reference. The band strengths we adopted for pyridine and water are $A c_{5} H_{5 N}=2.4 \times 10^{-18}$ and $A_{H_{2} O}=2 \times 10^{-16} \mathrm{~cm}$ molecules ${ }^{-1}$ taken from McMurtry et al. (2016) [14] and Dartois et al. (2015) [15], respectively. The sample thickness was calculated by:

$$
d=\frac{\mathrm{N}}{6.02 \times 10^{-23}} \cdot \frac{M}{\rho} \times 10^{4}[\mu \mathrm{m}]
$$

where $\mathrm{N}$ is the initial column density $\left(\right.$ molecules $\left./ \mathrm{cm}^{2}\right), M$ is the molar mass (g/molecules) and $\rho$ is the ice density $\left(1 \mathrm{~g} / \mathrm{cm}^{3}\right)$. 


\section{Results}

\subsection{Pure pyridine}

Pyridine $\left(\mathrm{C}_{5} \mathrm{H}_{5} \mathrm{~N}\right)$ is a liquid at room temperature with a vapor pressure close to that of water $\left(20 \mathrm{mmHg}\right.$ at $\left.25^{\circ} \mathrm{C}\right)$. The pure pyridine icy samples were prepared at $12 \mathrm{~K}$ and irradiated with $650 \mathrm{MeV} \mathrm{Zn}^{26+}$ and $90 \mathrm{keV} \mathrm{O}^{6+}$ and the chemical evolution during irradiation was followed using FTIR absorption spectroscopy as a function of projectile fluence.

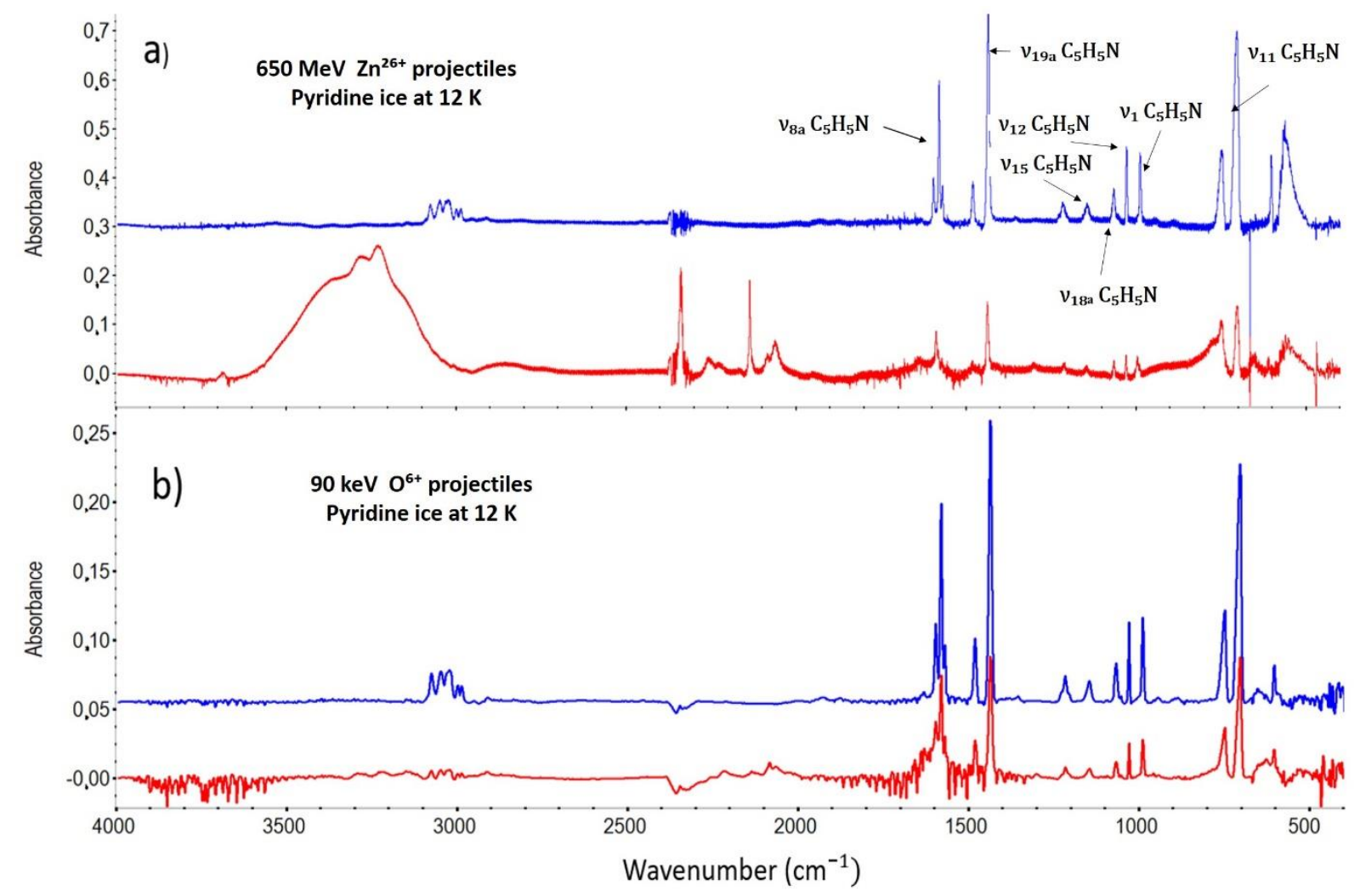

Fig. 1: FTIR spectra of (a) pyridine ice at $12 \mathrm{~K}$ before (upper blue line) and after irradiation with a fluence of $1.1 \times 10^{13}$ ions $\mathrm{cm}^{-2}$ (bottom red line) by $\mathrm{Zn}^{26+}(650 \mathrm{MeV})$ beam and of (b) pyridine ice at $12 \mathrm{~K}$ before (upper line)

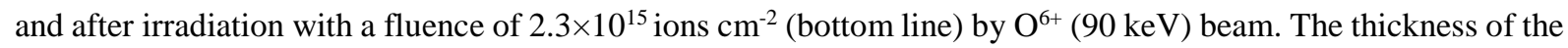
deposited layers is of the order of $8 \mu \mathrm{m}$. Assignments for the studied bands in this work are indicated on the spectrum. Note that spectra "before irradiation" were slightly shifted on the absorbance axis for better visibility. 


\subsubsection{Spectra}

Figure 1 presents the spectra of the pure pyridine ice samples before and after irradiation with $\mathrm{O}^{6+}(90 \mathrm{keV})$ and $\mathrm{Zn}^{26+}(650 \mathrm{MeV})$ at $12 \mathrm{~K}$. The infrared spectra of pyridine ice contain several peaks and bands corresponding to different excitation modes of vibrations at 711, 991, 1030, 1068, 1146, 1438 and $1581 \mathrm{~cm}^{-1}$, which are assigned to C-H out -of -deform, ring breathing, $\mathrm{C}-\mathrm{H}$ deform and ring stretching [14]. These spectra clearly show the decrease of the intensity of pyridine bands that can be related to the molecule destruction under irradiation. We observe that not only the area of the peaks present in the spectra of deposited ice layers decreases after irradiation, but also new peaks corresponding to new molecular species appear. Possible origins are formation of new species following radiolysis in the bulk, but also surface contamination from residual gas molecule absorption. $\mathrm{CO}_{2}$ and $\mathrm{CO}$ are identified via the 2342 and $2138 \mathrm{~cm}^{-1}$ bands, respectively, but also the $\mathrm{H}_{2} \mathrm{O}$ bands are seen at $3250 \mathrm{~cm}^{-1}, 1651 \mathrm{~cm}^{-1}$ and $760 \mathrm{~cm}^{-1}$ in the spectrum of pyridine ice after irradiation with $\mathrm{Zn}^{26+}(650 \mathrm{MeV})$ beam. As we can see in the FTIR spectrum of pyridine ice before irradiation, there was a small amount of $\mathrm{CO}_{2}$ visible at $2341 \mathrm{~cm}^{-1}$. It is due to the contamination by condensation of residual $\mathrm{CO}_{2}$ gas in the high vacuum chamber.

\subsubsection{Projectile fluence dependence}

To study the pyridine ice destruction by ion bombardment, we followed the evolution of seven absorption peaks: 711, 991, 1030, 1068, 1146, 1438 and $1581 \mathrm{~cm}^{-1}$ with projectile fluence. These peaks correspond to different modes of vibrations of distinct parts of the pyridine ring. According to the Beer-Lambert law, the area of an absorption peak is directly proportional to the column density. The disappearance of COMs was quantified by the "destruction cross section" $\sigma_{d}$, which was obtained from the exponential decrease of the peak area (A) as a function of the fluence $\mathrm{F}$ (i.e. the number of projectile ions per unit of area) [8, 13, 15-19]:

$$
\mathrm{A}(\mathrm{F})=A_{0} e^{-\sigma_{d} \mathrm{~F}}
$$

where $A_{0}$ is the initial absorption peak area. The evolution of the column density $(\mathrm{N})$ as a function of the ion fluence with the initial column density $N_{0}$ of pyridine ice is given by

$$
\mathrm{N}(\mathrm{F})=N_{0} e^{-\sigma_{d} \mathrm{~F}}
$$


$\mathrm{N}(\mathrm{F})$ and $\mathrm{A}(\mathrm{F})$ are measures of the remaining fraction of pyridine molecules in the ice after ion irradiation.

This simple approach takes into account the collisional fragmentation of the initial molecule, while neglecting a contribution of sputtering to the disappearance of the initial molecules as discussed in detail by Seperuelo Duarte et al. [13]. This assumption works for targets thick enough so that the contribution of sputtering, a surface effect, remains small compared to fragmentation, a bulk effect. This is indeed the case here for swift $\mathrm{MeV} / \mathrm{u}$ projectiles which traverse the target with a final velocity upon exit close to the initial velocity. Furthermore, sputtering of pyridine may be suppressed following the absorption of even small layers of water molecules from the residual gas ("layering") [18].

Figure 2 shows the evolution of the column density of the absorption peak at $711 \mathrm{~cm}^{-1}$ as a function of the projectile ion fluence during irradiation with a $\mathrm{Zn}^{26+}(650 \mathrm{MeV})$ beam in July 2019. Irradiation of pure pyridine was also performed at GANIL's low energy ion beam facility ARIBE with $90 \mathrm{keV} \mathrm{O}^{6+}$ beams. The experiment was repeated at three different periods: November 2017, April and November 2018 in order to verify the reproducibility. Table 1 summaries those three experimental conditions. The evolution of the column density of the peak at $711 \mathrm{~cm}^{-1}$ as a function of the projectile ion fluence is shown in Figure 3 


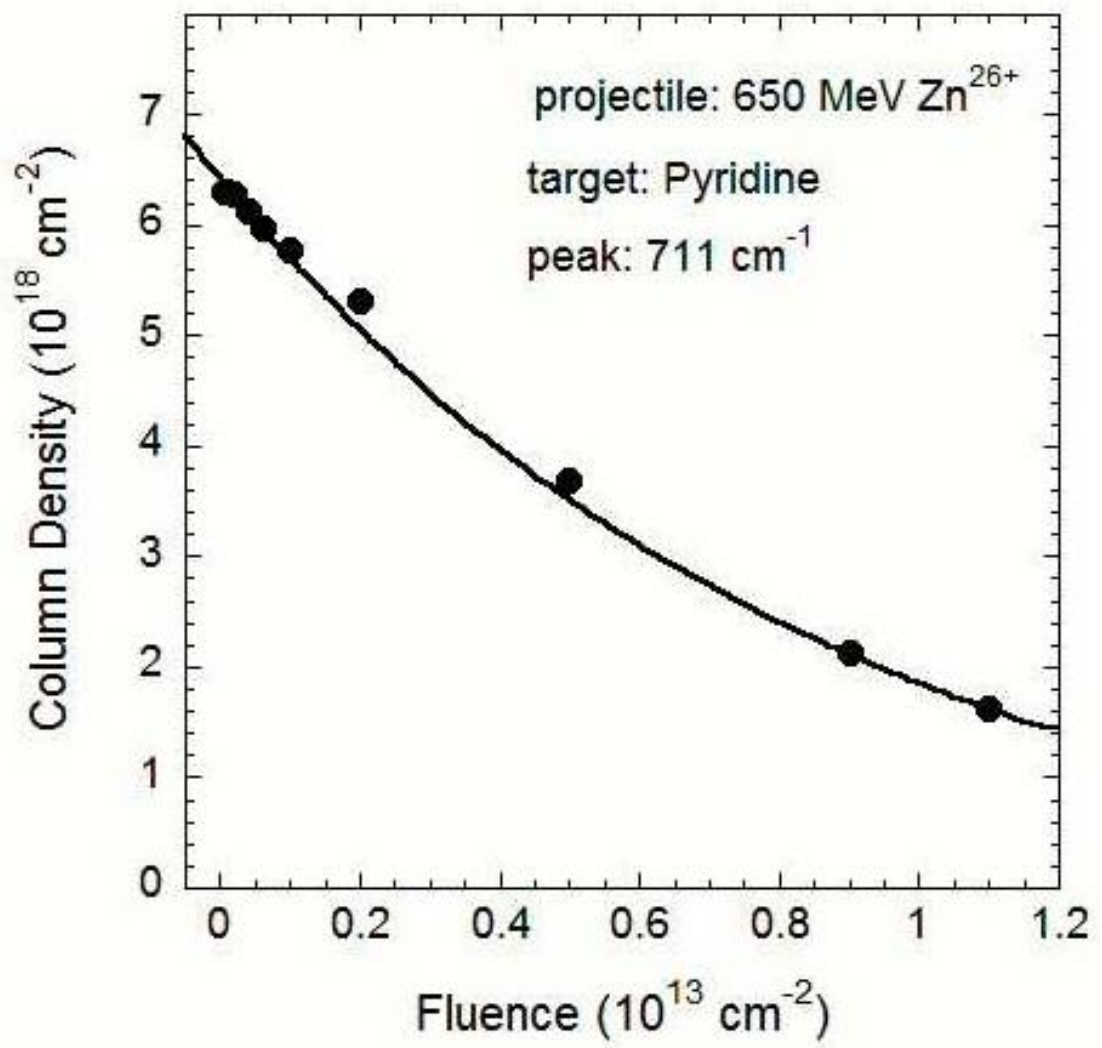

Fig. 2: Evolution of the area of the IR absorption peak of pyridine at $711 \mathrm{~cm}^{-1}$ with projectile fluence during irradiation with a $\mathrm{Zn}^{26+}(650 \mathrm{MeV})$ beam in July 2019.

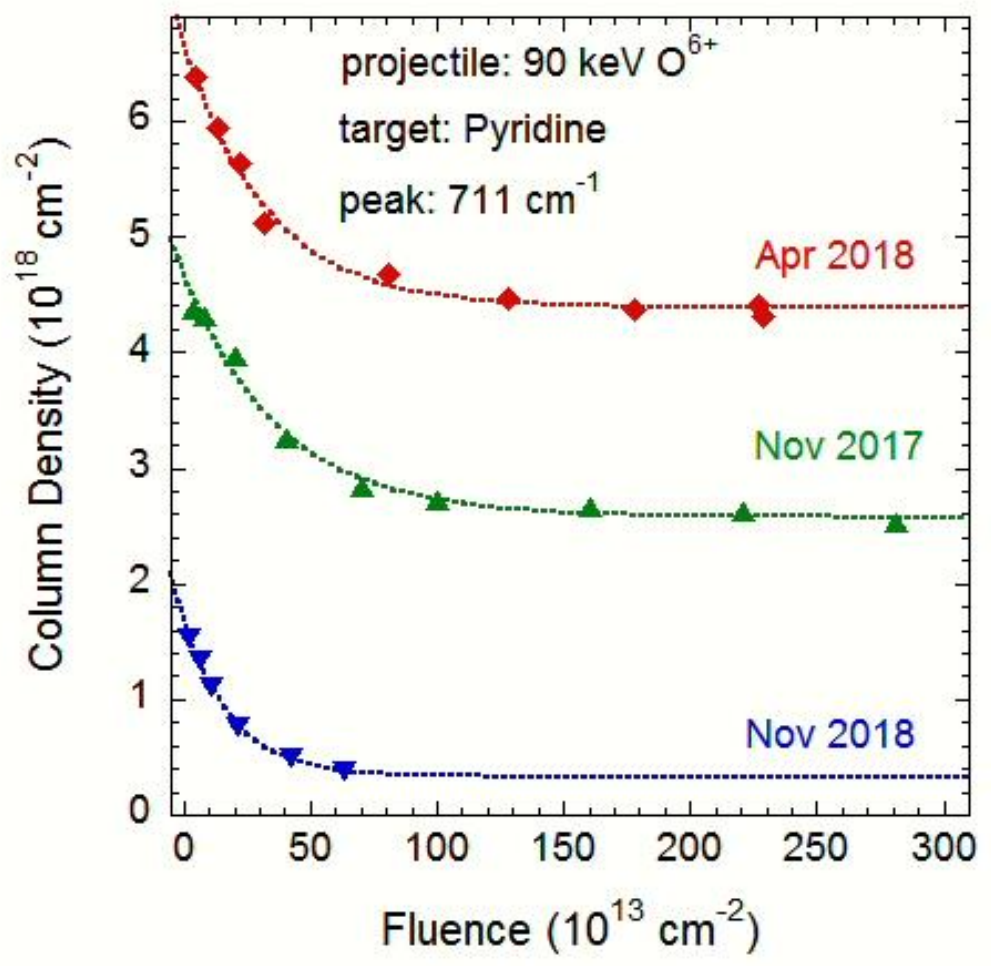

Fig. 3: Evolution of the area of the IR absorption peak of pyridine at $711 \mathrm{~cm}^{-1}$ with projectile fluence during irradiation with $90 \mathrm{keV} \mathrm{O}^{6+}$ for the three experiments. Summary of experimental conditions is presented in Table 1. 
The destruction cross section $\sigma_{\mathrm{d}}$ can be quantified from the fluence dependence of the area of selected absorption peak, which is proportional to the column density. The destruction cross section is determined from a best fit of the equation (2) to the experimental data obtained with the high energy with $\mathrm{Zn}^{26+}(650 \mathrm{MeV})$ beam. It is important to note that the energy loss of the projectiles in the thin ice film can be neglected with respect to the initial kinetic energy. The beam passes through the target with approximately constant velocity. This is not the case for the $90 \mathrm{keV} \mathrm{O}^{6+}$ beams with a range of about 0.4 microns in the ice film, smaller than the target thickness. Therefore, the projectiles are implanted, and a part of the ice films is not modified. In this case, a modified function taking into this zone of constant number of not irradiated molecules $\mathrm{N}_{2}$ and a linear term

$$
\mathrm{N}(\mathrm{F})=N_{0} e^{-\sigma_{d} \mathrm{~F}}+\mathrm{N}_{1} \mathrm{~F}+\mathrm{N}_{2}
$$

is used concerning the irradiation of pyridine with $\mathrm{O}^{6+}(90 \mathrm{keV})$ beam were $\mathrm{N}_{1}$ is related to a constant sputtering yield and $\mathrm{N}_{2}$ is the number of not irradiated molecules. Values of destruction cross section of pyridine ice obtained during irradiation of pyridine with $\mathrm{O}^{6+}(90 \mathrm{keV})$ and $\mathrm{Zn}^{26+}$ $(650 \mathrm{MeV})$ beam lines are displayed in Table 1.

Table 1 Date, beam energy, initial and final column density values, final projectile fluence, ice thickness and destruction cross section of pyridine (peak $711 \mathrm{~cm}^{-1}$ ) for each experiment analyzed in this work.

\begin{tabular}{|c|c|c|c|c|c|c|c|}
\hline Date & Beam & $\begin{array}{c}\text { Energy } \\
(\mathrm{MeV})\end{array}$ & $\begin{array}{c}\mathrm{N}_{\text {initial }} \\
\times \mathbf{1 0}^{18} \\
(\text { molecules } \\
\left.\mathbf{c m}^{-2}\right)\end{array}$ & $\begin{array}{c}\mathbf{N}_{\text {final }} \\
\times 10^{18} \\
\left(\text { molecules }^{-2}\right) \\
\left.\mathbf{c m}^{-2}\right)\end{array}$ & $\begin{array}{l}\mathbf{F}_{\text {final }} \\
\times \mathbf{1 0}^{13} \\
(\text { ions } \\
\left.\mathbf{c m}^{-2}\right) \\
\end{array}$ & $\begin{array}{c}\text { Thickness } \\
(\mu \mathrm{m})\end{array}$ & $\begin{array}{c}\text { Destruction } \\
\text { cross } \\
\text { section } \sigma_{\mathbf{d}} \\
\left(10^{-15} \mathbf{c m}^{2}\right) \\
\end{array}$ \\
\hline $\begin{array}{c}\text { November } \\
2017\end{array}$ & ${ }^{16} \mathrm{O}^{6+}$ & 0.09 & 4.02 & 2.54 & 281 & 5.30 & 1.66 \\
\hline April 2018 & ${ }^{16} \mathrm{O}^{6+}$ & 0.09 & 6.33 & 4.32 & 229 & 8.30 & 2.61 \\
\hline $\begin{array}{c}\text { November } \\
2018 \\
\end{array}$ & ${ }^{16} \mathrm{O}^{6+}$ & 0.09 & 1.60 & 0.40 & 63.7 & 2.10 & 3.53 \\
\hline July 2019 & ${ }^{70} \mathrm{Zn}^{26+}$ & 650 & 6.31 & 1.62 & 1.10 & 8.30 & 114 \\
\hline
\end{tabular}




\subsubsection{Stopping power dependence of destruction cross sections}

The stopping power $\mathrm{S}$ corresponds to the energy loss per unit of path length $\left(\frac{d E}{d x}\right)$. The destruction cross section as a function of the electronic stopping power $S_{\mathrm{e}}$ is shown in Figure 4. In addition to the data of the present work obtained with $90 \mathrm{keV} \mathrm{O}^{6+}$ and $650 \mathrm{MeV} \mathrm{Zn}^{26+}$ ions, a value obtained with high energy uranium projectiles (116 MeV) at GANIL's IRRSUD beamline taken from [19] was included. Stopping powers were calculated with the SRIM software [20]. Several authors have observed that the destruction cross section of molecules obeys a power law: $\sigma_{\mathrm{d}} \sim \mathrm{S}_{\mathrm{e}}{ }^{\mathrm{n}}$ (see e.g. $[8,13]$ and references therein). This is indeed what we also observe for pyridine, a slightly stronger than linear dependence $n=1.07$ is found in this specific case.

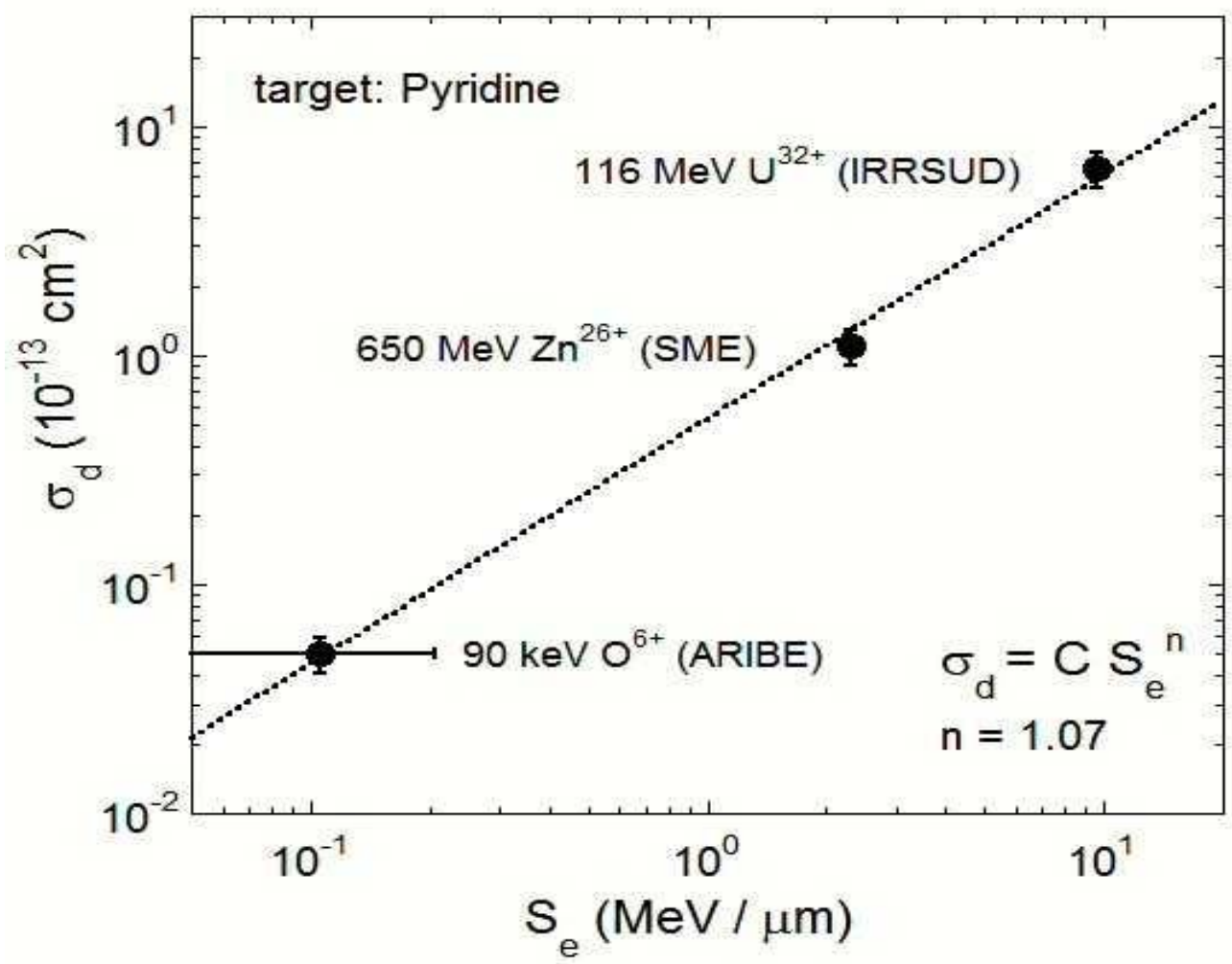

Fig. 4: The dependence of pyridine destruction cross section on the electronic stopping power. The cross sections are found to follow a power law as a function of the electronic stopping power $\sigma_{d} \sim S_{e}{ }^{n}$ with a slightly stronger than linear dependence $n=1.07$ in this specific case. The data obtained with uranium projectiles $(116 \mathrm{MeV})$ at GANIL's IRRSUD beamline is taken from [19]. The stopping power was calculated with the SRIM software [20]. 


\subsection{Pyridine in water ice}

In addition to pure pyridine ices, pyridine and water $\left(\mathrm{Py}: \mathrm{H}_{2} \mathrm{O}\right)$ icy samples at different molecular concentrations were irradiated with $\mathrm{Zn}^{26+}(650 \mathrm{MeV})$ and $\mathrm{O}^{6+}(90 \mathrm{keV})$. In all cases, prepared mixed ices before irradiation have amorphous and porous structure, which is reflected by the wide $\mathrm{OH}$ stretching band profile about $3300 \mathrm{~cm}^{-1}$ (in contrast to the finer peak observed with crystalline ice) and the presence of $\mathrm{OH}$ dangling bond signatures $[15,21]$. This comes closer to real conditions in space, where most molecules are mixed with water. Such a procedure allows us to verify if the icy environment modifies the radiation resistance of the initial molecule and/or the synthesis of daughter molecules and a comprehension of how the pyridine ice is affected in the presence of water ice. At low concentrations of pyridine, this would correspond to a COM embedded in a water matrix.

\subsubsection{Spectra}

Figure 5 shows the FTIR absorption spectra of three mixtures of Py with $\mathrm{H}_{2} \mathrm{O}$ before and after irradiation with $650 \mathrm{MeV} \mathrm{Zn}{ }^{26+}$ projectiles at $12 \mathrm{~K}$. The mixture $\mathrm{Py}: \mathrm{H}_{2} \mathrm{O}$ (1:20) was irradiated up to a fluence of $1.1 \times 10^{13}$ ions $\mathrm{cm}^{-2}$ (a), the mixture $\mathrm{Py}: \mathrm{H}_{2} \mathrm{O}(19: 1)$ ice up to $6 \times 10^{12}$ ions $\mathrm{cm}^{-}$ ${ }^{2}$ (b) and the mixture $\mathrm{Py}: \mathrm{H}_{2} \mathrm{O}(1: 0.73)$ ice up to $3.5 \times 10^{12}$ ions $\mathrm{cm}^{-2}$ (c). Spectra obtained with $90 \mathrm{keV} \mathrm{O}{ }^{6+}$ projectiles at $12 \mathrm{~K}$ are shown in Fig. 6: $\mathrm{Py}: \mathrm{H}_{2} \mathrm{O}(1: 5)$ ice, fluence $1.4 \times 10^{15}$ ions $\mathrm{cm}^{-2}$ (a); $\mathrm{Py}: \mathrm{H}_{2} \mathrm{O}(1: 1)$ ice, fluence $2.12 \times 10^{15}$ ions $\mathrm{cm}^{-2}$ (b); and $\mathrm{Py}: \mathrm{H}_{2} \mathrm{O}$ (3:1) ice, fluence $8.04 \times 10^{14}$ ions $\mathrm{cm}^{-2}$ (c), respectively. The decrease of the intensity of the pyridine bands (see above, sect. 3.1) due to the disappearance of this molecule is clearly observed. In contrast, the intensity of the broad bands of $\mathrm{H}_{2} \mathrm{O}$ around $3300 \mathrm{~cm}^{-1}, 1650 \mathrm{~cm}^{-1}$ and $803 \mathrm{~cm}^{-1}$ do not change drastically. They should decrease much more slowly compared to pyridine, since water is much more radiation resistant, although radiolysis and sputtering occur. The radiolysis of water is verified by the appearance of a band at $2850 \mathrm{~cm}^{-1}$ from the formation of $\mathrm{H}_{2} \mathrm{O}_{2}$. In fact, the intensity of the water bands may even increase due to a persistent deposition of water from the residual gas. Other new bands also appear after irradiation of pyridine-water mixed ices corresponding to the formation of new molecular species: a $\mathrm{CO}_{2}$ band is seen at 2342 $\mathrm{cm}^{-1}$ while a $\mathrm{CO}$ band appears at $2138 \mathrm{~cm}^{-1}$ (indicating that new species containing atoms coming from both initial molecules). Note that their column density increases as a function of ion fluence (therefore $\mathrm{CO}_{2}$ molecule is formed during ion irradiation and not due to contamination by condensation of residual gas during sample preparation). 

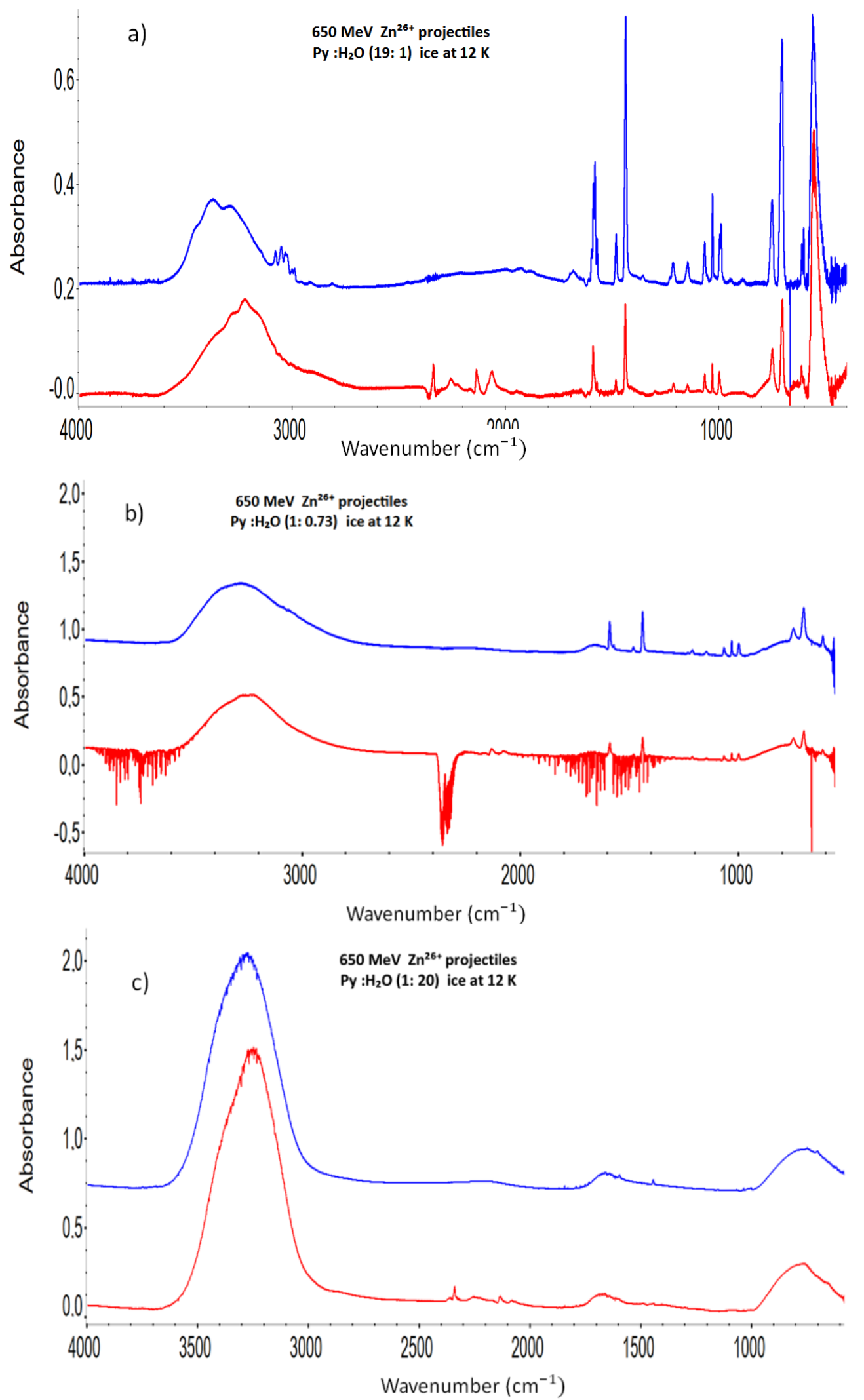

Fig. 5: FTIR spectra of (a) $\mathrm{Py}: \mathrm{H}_{2} \mathrm{O}$ (19:1) ice before (upper line) and after irradiation with a fluence of $6 \times 10^{12}$ ions $\mathrm{cm}^{-2}$ (bottom line), of (b) $\mathrm{Py}: \mathrm{H}_{2} \mathrm{O}$ (1:0.73) ice before (upper line) and after irradiation with a fluence of $3.5 \times 10^{12}$ ions $\mathrm{cm}^{-2}$ and of (c) $\mathrm{Py}: \mathrm{H}_{2} \mathrm{O}(1: 20)$ ice before (upper line) and after irradiation with a fluence of $1.1 \times 10^{13}$ ions $\mathrm{cm}^{-2}$ (bottom line) by $\mathrm{Zn}^{26+}(650 \mathrm{MeV})$ beams at $12 \mathrm{~K}$. Spectra "before irradiation" were slightly shifted on the absorbance axis for better visibility. 

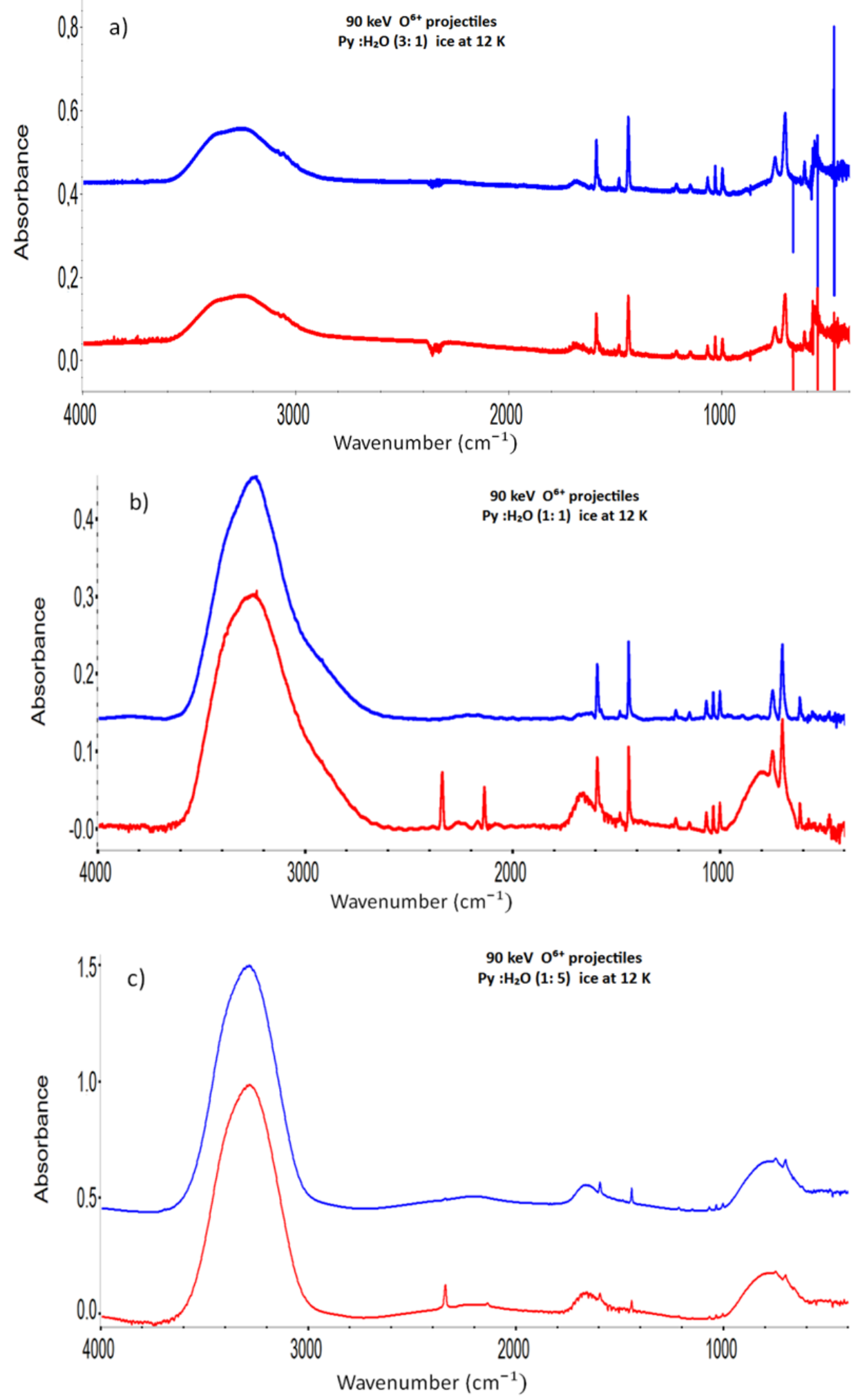

Fig. 6: FTIR spectra of (a) $\mathrm{Py}: \mathrm{H}_{2} \mathrm{O}$ (3:1) ice before (upper line) and after irradiation with a fluence of $8 \times 10^{14}$ ions $\mathrm{cm}^{-2}$ (bottom line), of (b) $\mathrm{Py}: \mathrm{H}_{2} \mathrm{O}$ (1:1) ice before (upper line) and after irradiation with a fluence of $2.12 \times 10^{15}$ ions $\mathrm{cm}^{-2}$ and of (c) $\mathrm{Py}: \mathrm{H}_{2} \mathrm{O}$ (1:5) ice before (upper line) and after irradiation with a fluence of $1.4 \times 10^{15}$ ions $\mathrm{cm}^{-2}$ (bottom line) by $\mathrm{O}^{6+}(90 \mathrm{keV})$ beams at $12 \mathrm{~K}$. Spectra "before irradiation" were slightly shifted on the absorbance axis for better visibility. 


\subsubsection{Destruction cross sections as function of pyridine concentration}

As for the study of pure pyridine ice destruction by $\mathrm{Zn}^{26+}(650 \mathrm{MeV})$ and $\mathrm{O}^{6+}(90 \mathrm{keV})$, we use the same equations (1) and (3), respectively, to follow the evolution of the peak area as a function of the projectile fluence for the mixtures $\mathrm{Py}: \mathrm{H}_{2} \mathrm{O}$ at different molecular concentrations. Destruction cross sections are determined from a best fit of the corresponding equation to the peak areas as a function of fluence. Again, we analyzed the evolution of the areas of six pyridine absorption peaks at 991, 1030,1068, 1146, 1438 and $1581 \mathrm{~cm}^{-1}$, which do not overlap with water and/or formed daughter species. The results for the cross sections obtained by this procedure for each of the above mentioned absorption peaks in the four experimental campaigns are summarized in Table $2\left(650 \mathrm{MeV} \mathrm{Zn}^{26+}\right.$ beam) and Table $3\left(90 \mathrm{keV} \mathrm{O}^{6+}\right)$. As a general trend observed in all experimental campaigns, the destruction cross section decreases with increasing pyridine concentration.

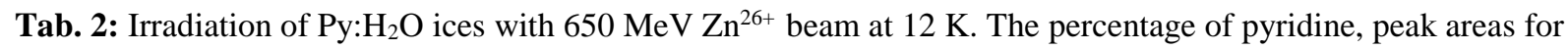
the indicated IR absorption lines and destruction cross section are given.

\begin{tabular}{|c|c|c|c|c|c|c|c|}
\hline $\begin{array}{l}\text { Mixture } \\
\mathrm{Py}: \mathrm{H}_{2} \mathrm{O}\end{array}$ & $\begin{array}{l}\text { Pyridine } \\
\text { percentage } \\
(\%)\end{array}$ & $\begin{array}{l}\text { Peak } \\
991 \mathrm{~cm}^{-1} \\
\sigma_{\mathrm{d}}\left(10^{-13} \mathrm{~cm}^{2}\right)\end{array}$ & $\begin{array}{l}\text { Peak } \\
1030 \mathrm{~cm}^{-1} \\
\sigma_{d}\left(10^{-13} \mathrm{~cm}^{2}\right)\end{array}$ & $\begin{array}{c}\text { Peak } \\
1068 \mathrm{~cm}^{-1} \\
\sigma_{d}\left(10^{-13} \mathrm{~cm}^{2}\right)\end{array}$ & $\begin{array}{l}\text { Peak } \\
1146 \mathrm{~cm}^{-1} \\
\sigma_{\mathrm{d}}\left(10^{-13} \mathrm{~cm}^{2}\right)\end{array}$ & $\begin{array}{l}\text { Peak } \\
1438 \mathrm{~cm}^{-1} \\
\sigma_{d}\left(10^{-13} \mathrm{~cm}^{2}\right)\end{array}$ & $\begin{array}{l}\text { Peak } \\
1581 \mathrm{~cm}^{-1} \\
\sigma_{\mathrm{d}}\left(10^{-13} \mathrm{~cm}^{2}\right)\end{array}$ \\
\hline$(1: 20)$ & 4.76 & 3.44 & 6.34 & 6.72 & 8.40 & 10.3 & 4.03 \\
\hline (1:4) & 20 & 3.16 & 2.71 & 1.71 & 6.50 & 6.50 & 2.66 \\
\hline$(1: 0.73)$ & 58 & 1.02 & 1.12 & 1.12 & 1.58 & - & 2.96 \\
\hline$(3: 1.11)$ & 73 & 1.17 & 1.47 & 1.23 & 1.28 & 1.34 & 1.22 \\
\hline$(19: 1)$ & 95 & 1.17 & 1.29 & 1.03 & 1.22 & 1.46 & 1.26 \\
\hline
\end{tabular}


Tab. 3: Irradiation of $\mathrm{Py}: \mathrm{H}_{2} \mathrm{O}$ ices with $\mathrm{O}^{6+}(90 \mathrm{keV})$ beams at $12 \mathrm{~K}$ in November 2017 (a), April 2018 (b) and November 2018 (c). The percentage of pyridine, peak areas for the indicated IR absorption lines and destruction cross section are given.

\begin{tabular}{|c|c|c|c|c|c|c|c|}
\hline $\begin{array}{c}\text { Mixture } \\
\mathrm{Py}: \mathrm{H}_{2} \mathrm{O}\end{array}$ & $\begin{array}{c}\text { Pyridine } \\
\text { percentage } \\
(\%)\end{array}$ & $\begin{array}{c}\text { Peak } \\
991 \mathrm{~cm}^{-1} \\
\sigma_{\mathrm{d}}\left(10^{-15}\right. \\
\left.\mathrm{cm}^{2}\right)\end{array}$ & $\begin{array}{c}\text { Peak } \\
1030 \mathrm{~cm}^{-1} \\
\sigma_{\mathbf{d}}\left(10^{-15}\right. \\
\left.\mathrm{cm}^{2}\right)\end{array}$ & $\begin{array}{c}\text { Peak } \\
1068 \mathrm{~cm}^{-1} \\
\sigma_{\mathrm{d}}\left(10^{-15}\right. \\
\left.\mathrm{cm}^{2}\right)\end{array}$ & $\begin{array}{c}\text { Peak } \\
1146 \mathrm{~cm}^{-1} \\
\sigma_{\mathrm{d}}\left(10^{-}\right. \\
\left.15 \mathrm{~cm}^{2}\right)\end{array}$ & $\begin{array}{c}\text { Peak } \\
1438 \mathrm{~cm}^{-1} \\
\sigma_{\mathrm{d}}\left(10^{-15}\right. \\
\left.\mathrm{cm}^{2}\right)\end{array}$ & $\begin{array}{c}\text { Peak } \\
1581 \mathrm{~cm}^{-1} \\
\sigma_{\mathrm{d}}\left(10^{-15}\right. \\
\left.\mathbf{c m}^{2}\right)\end{array}$ \\
\hline \multicolumn{8}{|c|}{ a) November 2017} \\
\hline$(1: 16.5)$ & 6 & 6.30 & 1.00 & 8.41 & 2.65 & 8.47 & 11.27 \\
\hline$(1: 7.25)$ & 12 & 4.00 & 5.71 & 6.25 & 5.54 & 5.00 & 5.67 \\
\hline$(1: 5)$ & 16.6 & 4.57 & 6.40 & 5.80 & 5.17 & 5.17 & 5.07 \\
\hline$(1.5: 1)$ & 60 & 6.25 & 3.33 & 4.37 & 3.00 & 3.00 & 2.07 \\
\hline \multicolumn{8}{|c|}{ b) April 2018} \\
\hline$(1: 11)$ & 9 & 7.40 & 7.10 & 8.30 & 7.30 & 7.00 & 6.90 \\
\hline$(1: 5)$ & 16.7 & 6.00 & 7.00 & 6.00 & 7.80 & 6.40 & 6.00 \\
\hline$(1: 1)$ & 50 & 5.60 & 5.60 & 4.60 & 5.60 & 4.60 & 5.56 \\
\hline$(3: 0.6)$ & 83 & 5.60 & 5.60 & 6.00 & 7.20 & 4.00 & 1.90 \\
\hline \multicolumn{8}{|c|}{ c) November 2018} \\
\hline$(1: 14)$ & 7 & 6.40 & - & - & 6.40 & 10.57 & - \\
\hline$(1: 7)$ & 14 & 4.60 & 8.13 & 6.90 & 5.80 & 3.90 & 8.51 \\
\hline$(1: 3)$ & 25 & 5.80 & 5.20 & 5.50 & - & 4.60 & 7.78 \\
\hline$(1: 1.5)$ & 40 & 4.60 & 2.92 & 6.87 & 5.76 & 3.91 & 5.62 \\
\hline$(3: 1)$ & 75 & 5.08 & 5.10 & 3.83 & 4.67 & 5.25 & 4.05 \\
\hline
\end{tabular}




\section{Discussion}

As can be seen from Tables 2 and 3, the intensity of some bands decreases more rapidly with projectile fluence than that of others, thus yielding slightly different values of the associated destruction cross section. In published studies on ion irradiation of COMs (nucleobases and amino acids), individual peaks and/or an average value (mean value of all analyzed peaks) were used to determine the radiation sensitivity [17, 22-27]. If such data are to be applied e.g. for estimating survival times of COMs exposed in space to cosmic rays, the most pertinent choice strictly speaking, the effective destruction cross section for a molecule should correspond to the highest value. Another possibility to analyze the data is the following: we propose to sum up all the areas of the observed absorption peaks and perform the above mentioned fitting procedure with equations (1) and (3) on the summed-up values. This approach is based on the study of other COM-adenine, which exhibits a large absorption region between 3400 and 2000 $\mathrm{cm}^{-1}$ referred to as "alpha band" (see e.g. [17,19]). In a certain sense, the sum of all resolvable vibration mode peak areas would correspond to such a broad absorption feature for COMs.

However, some authors work with individual absorption peak values, which we present in Tables 2 and 3. The average cross sections, i.e. the mean value of the cross sections obtained from the individual peaks, are shown in Table 4. In this table, we also included the results obtained from the sum over the six analyzed absorption peaks. These two quantities are plotted in Figure 7a-d. As can be seen, in all cases, a clear tendency is observed: ices of pure pyridine are more resistant to swift ion irradiation than ices of pyridine dissolved in water. The destruction cross sections $\sigma_{\mathrm{d}}(\%)$ decrease with increasing percentage of pyridine in the water ice. Figure 8 compares the results obtained with the two different ion beams. Averaged destruction cross sections, normalized to $\sigma_{\mathrm{d}}=1$ for $100 \%$ pure pyridine as a function of pyridine percentage are shown for $\mathrm{Zn}^{26+}(650 \mathrm{MeV})$ and $\mathrm{O}^{6+}(90 \mathrm{keV})$. The effect is obviously stronger for the higher energy beam $\mathrm{Zn}^{26+}(650 \mathrm{MeV})$ than for the lower energy beam $90 \mathrm{keV} \mathrm{O}^{6+}$.

This finding is related to the energy loss mechanisms involved: (1) elastic collisions with the target nuclei (nuclear stopping $\mathrm{S}_{\mathrm{n}}$ ), (2) inelastic collisions involving the target electrons (electronic stopping $\mathrm{S}_{\mathrm{e}}$ by excitation and ionization) and (3) electronic excitation promoted by the potential energy of highly charged ions (due to electron capture from the target). The latter can be neglected here for radiolysis in the bulk, but might contribute a small effect to sputtering of molecules from the surface. For the high velocity $\mathrm{Zn}^{26+}(650 \mathrm{MeV})$ projectiles, electronic 
stopping $\mathrm{S}_{\mathrm{e}}$ dominates energy deposition and $\mathrm{S}_{\mathrm{n}}$ can be neglected. For $\mathrm{O}^{6+}(90 \mathrm{keV})$ projectiles, $\mathrm{S}_{\mathrm{e}}$ dominates upon entrance, but while slowing down its contribution becomes less and less important, while the contribution of $S_{n}$ increases until the projectiles are stopped when reaching final projectile range (implantation). This behavior is the reason for -at first glance- large and somewhat unusual error bar for $\mathrm{S}_{\mathrm{e}}$ of $\mathrm{O}^{6+}(90 \mathrm{keV})$ in Figure 4. The upper limit corresponds to the initial electronic energy loss; the data point was put at a mean value covering the trajectory until zero velocity.
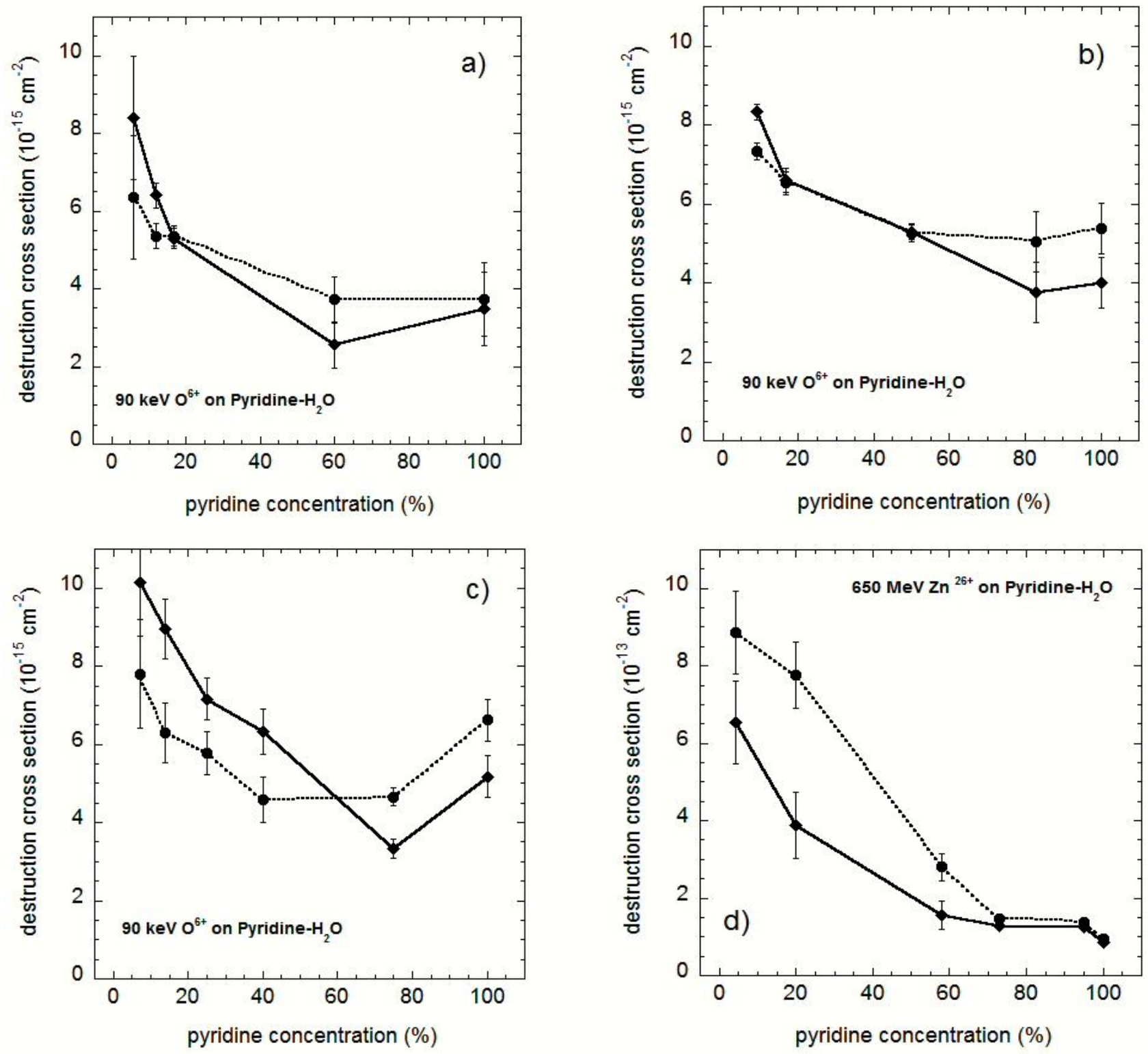

Fig. 7: Destruction cross sections as a function of pyridine percentage: average destruction cross section (dotted line) and destruction cross section from the sum of all peak areas (full line). See text for more details. a)-c) with $\mathrm{O}^{6+}(90 \mathrm{keV})$ beams at $12 \mathrm{~K}$ in November 2017, April 2018 and November 2018, respectively. d) $\mathrm{Zn}^{26+}(650$ MeV) beam, July 2019. 
Tab. 4: Destruction cross sections values obtained for the experiment with $\mathrm{O}^{6+}(90 \mathrm{keV})$ (mean values of individual peaks, sum over all peak areas) in: a) November 2017, b) April 2018 and c) November 2018, and d) for experiment in July 2019 with $650 \mathrm{MeV} \mathrm{Zn}^{26+}$ ions.

\begin{tabular}{|c|c|c|c|}
\hline $\begin{array}{l}\text { Mixture } \\
\mathrm{Py}: \mathrm{H}_{2} \mathrm{O}\end{array}$ & $\begin{array}{c}\text { Pyridine } \\
\text { percentage }(\%)\end{array}$ & $\begin{array}{c}\text { Destruction } \\
\text { cross section from the } \\
\text { sum of all peak areas } \\
\left(10^{-15} \mathrm{~cm}^{2}\right)\end{array}$ & $\begin{array}{l}\text { Average destruction } \\
\text { cross section } \\
\left(10^{-15} \mathbf{c m}^{2}\right)\end{array}$ \\
\hline \multicolumn{4}{|c|}{ a) November 2017} \\
\hline$(1: 16.5)$ & 6 & 8.46 & 6.35 \\
\hline$(1: 7.25)$ & 12 & 6.41 & 5.36 \\
\hline$(1: 5)$ & 16.6 & 5.30 & 5.36 \\
\hline$(1.5: 1)$ & 60 & 2.56 & 3.72 \\
\hline$(1: 0)$ & 100 & 3.48 & 3.72 \\
\hline \multicolumn{4}{|c|}{ b) April 2018} \\
\hline$(1: 11)$ & 9 & 8.33 & 7.33 \\
\hline$(1: 5)$ & 16.7 & 6.61 & 6.63 \\
\hline$(1: 1)$ & 50 & 5.30 & 5.26 \\
\hline$(3: 0.6)$ & 83 & 3.76 & 5.05 \\
\hline$(1: 0)$ & 100 & 4.00 & 5.38 \\
\hline \multicolumn{4}{|c|}{ c) November 2018} \\
\hline$(1: 14)$ & 7 & 10.15 & 7.80 \\
\hline$(1: 7)$ & 14 & 8.95 & 6.30 \\
\hline$(1: 3)$ & 25 & 7.16 & 5.78 \\
\hline$(1: 1.5)$ & 40 & 6.34 & 4.95 \\
\hline$(3: 1)$ & 75 & 3.34 & 4.66 \\
\hline$(1: 0)$ & 100 & 5.18 & 6.72 \\
\hline \multicolumn{4}{|c|}{ d) July 2019} \\
\hline $\begin{array}{l}\text { Mixture } \\
\mathrm{Py}: \mathrm{H}_{2} \mathrm{O}\end{array}$ & $\begin{array}{c}\text { Pyridine } \\
\text { percentage }(\%)\end{array}$ & $\begin{array}{c}\text { Destruction } \\
\text { cross section from the } \\
\text { sum of all peak areas } \\
\qquad\left(10^{-13} \mathrm{~cm}^{2}\right)\end{array}$ & $\begin{array}{l}\text { Average destruction } \\
\text { cross section } \\
\left(10^{-13} \mathbf{c m}^{2}\right)\end{array}$ \\
\hline$(1: 20)$ & 4.76 & 8.86 & 6.54 \\
\hline$(1: 4)$ & 20 & 7.76 & 3.88 \\
\hline$(1: 0.73)$ & 58 & 4.82 & 1.56 \\
\hline$(3: 1.11)$ & 73 & 1.47 & 1.28 \\
\hline$(19: 1)$ & 95 & 1.38 & 1.24 \\
\hline$(1: 0)$ & 100 & 0.94 & 0.85 \\
\hline
\end{tabular}


Figure 4 contains important information allowing the estimation of half-life times of pyridine molecules exposed to cosmic rays in space, since it presents a scaling law with the amount of deposited energy per molecule (dose) quantified by $\mathrm{S}_{\mathrm{e}}$ (see sect. 5). The destruction cross sections scale with a power $\mathrm{n}$ of $\mathrm{S}_{\mathrm{e}}, \sigma_{\mathrm{d}} \sim \mathrm{S}_{\mathrm{e}}{ }^{\mathrm{n}}$, with a stronger than linear dependence. This behavior is universal and has been observed for many simple and more complex molecules [8, $16,17,27]$.

Similar experiments on the radiation stability of COMs in solid water were performed with amino acids (glycine, alanine, phenylalanine) [23, 24] and the nucleobases thymine [25], which resembles the structure of pyridine in that it contains one aromatic ring. Also, the photolysis of PAHs (polycyclic aromatic hydrocarbons) in water ice matrix was investigated (as an example, see [28]). The results reported with thymine show the same tendency as those observed here with pyridine: the radiation resistance of thymine decreases as the dilution of thymine in water increases [25]. The same is true for photolysis of PAHs in solid water, destruction of the aromatic PAHs is more efficient for lower than for higher PAH concentrations [28]. This shows that a water environment significantly modifies the radiation resistance of the initial molecule.

Several experimental and theoretical studies have been carried out on the protonation of pyridine in water clusters as a function of the number of attached water molecules [32-34]. It has been shown that protonation of the pyridine molecule (pyridinyl radical) in a cluster of hydrogen-bonded water molecules occurs by abstracting a hydrogen ion from a water molecule. The result is a hydrated cation $\left(\mathrm{PyrH}^{+}\right)$, charge-balanced by a hydroxyl group. The efficiency of the formation of the pyridinyl radical depends on the number of water molecules. Experimentally it has been evidenced that at least four water molecules were necessary to observe one protonated pyridine molecule [33]. The observation of the splitting of the water due to the presence of a pyridine molecule in the clusters may have also applications in the present studies of ion irradiation of pyridine-water ice samples. It is worth noting that reactive the radical $\mathrm{OH}$ can be formed not only via direct water molecule fragmentation by also "build up" due to formation $\mathrm{Py} \bullet \mathrm{nH}_{2} \mathrm{O}$ complexes in the ice.

The molecules may be fragmented directly by the impact of the projectile leading to ionization/excitation $\left(\mathrm{S}_{\mathrm{e}}\right)$ or knock-on displacement of atoms $\left(\mathrm{S}_{\mathrm{e}}\right)$. An indirect effect is also possible: reactive species (radicals) from radiolysis of the water molecules (or even the COM) may contribute to the destruction of neighboring molecules. The observation that the observed 
effect is stronger with the higher velocity projectiles in the electronic stopping regime points toward this argument. Indeed, more radicals are produced along the track within a track radius much larger than for the slower projectiles, due to secondary ionization by high energy delta electrons [8]. Furthermore, $\mathrm{H}_{2} \mathrm{O}$ may act as proton acceptor thus enhancing chemical reactions following radiolysis in ices [24]. Also, COMs ionized in a primary event may show a higher probability for recombination with an electron from a neighboring molecule so that ionization becomes less efficient at high COM concentrations [28].

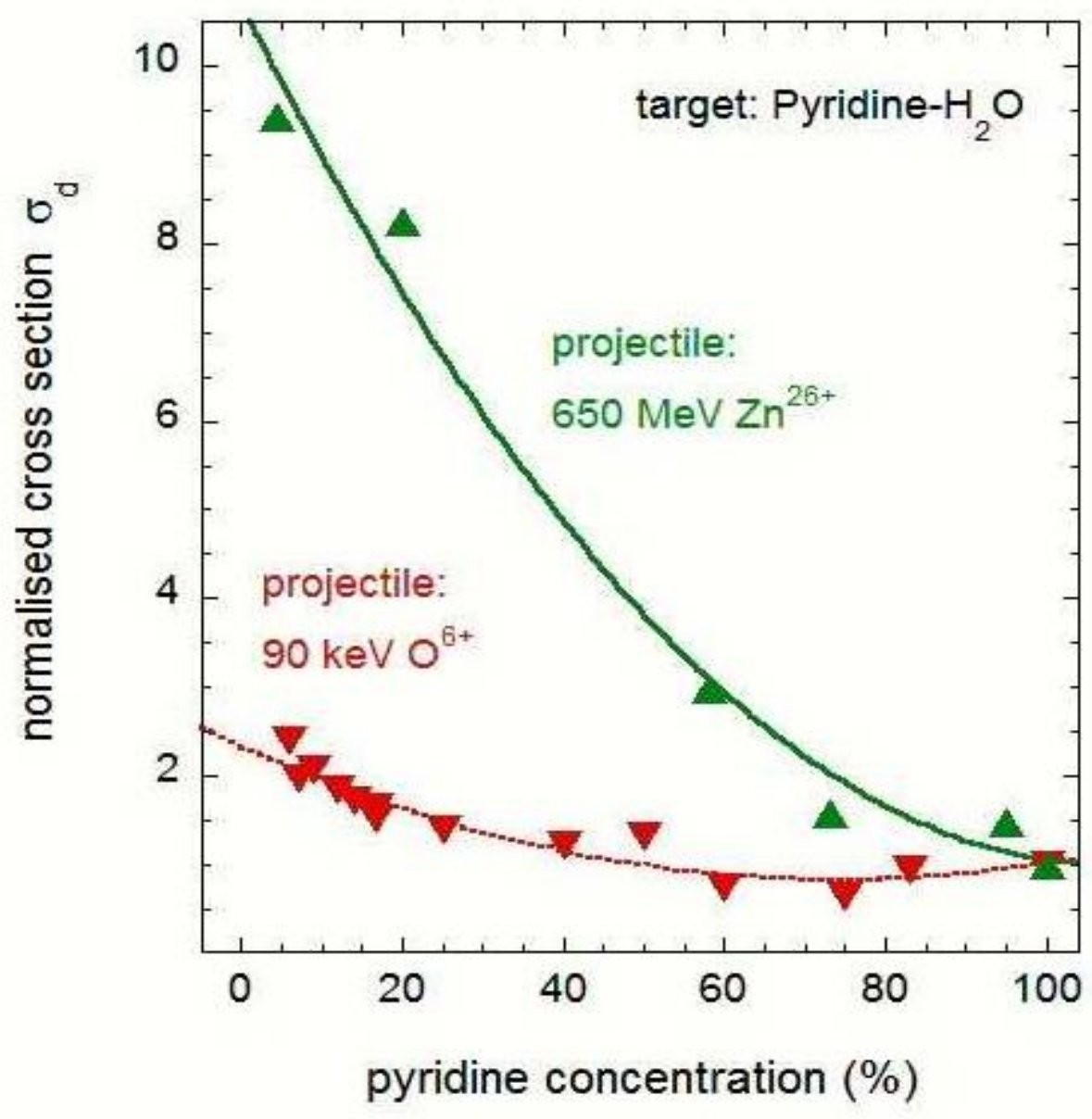

Fig. 8: Averaged destruction cross sections, normalized to $\sigma_{\mathrm{d}}=1$ for $100 \%$ pure pyridine as a function of pyridine percentage for $\mathrm{Zn}^{26+}(650 \mathrm{MeV})$ (triangles) and $\mathrm{O}^{6+}(90 \mathrm{keV})$ (upside-down triangles).

Upon a closer inspection of Figures 7 and 8, one might speculate about a minimum of the curve at concentration close to $70 \%$. This could be related to this recombination effect and is supported by observations with hydrated nucleobase clusters [29-30]. Here the nano- 
environment (surrounding molecules) has a significant influence on the fragmentation dynamics, providing an overall protective effect: molecular fragmentation is strongly reduced. In this context it is worth to mention that we also performed experiments on the emission of secondary ions from pure water ice and mixed pyridine-water ice $[10,31]$ irradiated with 90 $\mathrm{keV} \mathrm{O}^{6+}$ projectiles. Experimental details are presented in [31]. As shown in [10], mass spectra of positive secondary ions from pyridine ice shown as most prominent peak that of pyridine (or hydrogenated pyridine) at $\mathrm{m}_{\mathrm{Py}} / \mathrm{z}=79$. At higher masses $\mathrm{m}>\mathrm{m}_{\mathrm{Py}}$, clusters of pyridine $(\mathrm{Py})_{\mathrm{n}}$ with $\mathrm{n}$ up to 4 are visible. Strikingly, with the $\mathrm{Py}-\mathrm{H}_{2} \mathrm{O}$ mixed ice, the smallest cluster $(\mathrm{Py})_{2}$ is still observed, but not the larger clusters $n>2$. Pyridine is effectively embedded in $\mathrm{H}_{2} \mathrm{O}$, which seems to effectively surround the COM pyridine. Further studies with ices of lower pyridine concentration would be useful.

\section{Outlooks}

The survival times of COMs in outer space depends on their radio-resistance to the impact of energetic particles to which they are continuously exposed. Taking into account the measured scaling of destruction cross sections (Figure 4) and the flux distribution of ionizing particles, the half life time of COMs in space environments can be estimated [8,17, 25-27]. To give an example, deep inside a dense molecular cloud, where only secondary UV photons induced by cosmic rays are present and primary UV radiation from surrounding stars cannot penetrate, the survival time of solid adenine exposed to cosmic rays was estimated to be of the order of 10 Myr [17]. This time is comparable to the lifetime of dense molecular clouds and, consequently. It seems likely that adenine may survive in the "nurseries" of star formation.

The destruction cross sections reported in the present work are of the same order that those observed for adenine so that the same half life time could be expected for pyridine exposed to cosmic rays inside a dense cloud. The estimated survival times of thymine [23] are more than one order of magnitude lower in a similar space environment. If embedded in water, the survival times would be significantly shorter (by up to nearly an order of magnitude, see Figure 8).

Finally, we note that understanding of fragmentation of COMs mixed with water is of significance for radiation biology (radioprotection, ion beam therapy) [35, 36]. In all living beings, be it humans, animals or plants, biomolecules are always immersed in a water 
environment, but at higher temperature than those relevant for space environments [23-25]. Thus, it would be interesting to perform studies on radio-resistance of COMs at higher temperatures up to about $350 \mathrm{~K}$.

\section{Acknowledgements}

We thank the staff of CIMAP and GANIL and among them all in particular T. Been, C. Feierstein, T. Madi, J.M. Ramillon, F. Ropars, P. Rousseau, P. Voivenel, L. Maunoury and our collaborators B. Augé, C. Desfrançois, F. Lecomte, B. Manil, R. Martinez, Gabriel S.V. Muniz and N. Nieuwjaer. We gratefully acknowledge funding from INSERM-INCa (Grant BIORAD), Région Normandie Fonds Européen de Développement Régional - FEDER Programmation 2014-2020, and a Ph. D. grant from Région Normandie RIN 2018. The infrastructure of GANIL (Grand Accélérateur National d'Ions Lours, Caen, France) was used to do the research presented here. The research of Z.K. was supported by ENSAR2-Access-TNA GANIL and VEGA - the Slovak Grant Agency for Science (grant No. 2/0023/18). 


\section{References}

[1] P. Ehrenfreund, S. B. Charnley, Annu. Rev. Astron. Astrophys. 38, 427 (2000)

[2] Y. Oba, Y. Takano, H. Naraoka, N. Watanabe, A. Kouchi, Nat. Commun. 10, 4413 (2019)

[3] E. Dartois, C. Engrand, R. Brunetto, J. Duprat, T. Pino, E. Quirico, L. Remust, N. Bardin, G. Briani, S. Mostefaoui, G. Morinaud, B. Crane, N. Szwec, L. Delauche, F. Jamme, Ch. Sandt, P. Dumas, Icarus 224, 243 (2013)

[4] Z. Martins, O. Botta, M. L. Fogel, M. A. Sephton, D. P. Glavin, J. S. Watson, J. P. Dworkin, A. W. Schwartz, P. Ehrenfreund, Earth Planet. Sci. Lett. 270, 130 (2008) [5] J.E. Elsila, D.P. Glavin, J.P. Dworkin, Meteorit. Planet. Sci. 44, 1323 (2009)

[6] E. Quirico, L. V. Moroz, B. Schmitt, G. Arnold, M. Faure, P. Beck, L. Bonal, M. Ciarniello, F. Capaccioni, G. Filacchione, S. Erard, C. Leyrat, D. Bockelée-Morvan, A. Zinzi, E. Palomba, P. Drossart, F. Tosi, M. T. Capria, M. C. De Sanctis, A. Raponi, S. Fonti, F. Mancarella,V. Orofino, A. Barucci, M. I. Blecka, R. Carlson, D. Despan, A. Faure, S. Fornasier, M. S. Gudipati, A. Longobardo, K. Markus, V. Mennella, F. Merlin, G. Piccioni, B. Rousseau, F. Taylor, Rosetta VIRTIS team, Icarus 272, 32 (2016)

[7] K. Altwegg, H. Balsiger, A. Bar-Nun, J-J. Berthelier, A. Bieler, P. Bochsler, C. Briois, U. Calmonte, M. R. Combi, H. Cottin, J. De Keyser, F. Dhooghe, B. Fiethe, S. A. Fuselier, S. Gasc, T. I. Gombosi, K. C. Hansen, M. Haessig, A. Jäckel, E. Kopp, A. Korth, L. Le Roy, U. Mall, B. Marty, O. Mousis, T. Owen, H. Rème, M. Rubin, T. Sémon, Chia-Yu Tzou, J. H. Waite and P. Wurz, Science Advances 2, e1600285 (2016)

[8] H. Rothard, A. Domaracka, P. Boduch, M. E. Palumbo, G. Strazzulla, E. F. da Silveira, E. Dartois, J. Phys. B 50, 062001 (2017)

[9] B. Augé, E. Dartois, C. Engrand, J. Duprat, M. Godard, L. Delauche, N. Bardin, C. Mejía, R. Martinez, G. Muniz, A. Domaracka, P. Boduch, H. Rothar, Astron. Astrophys. 592, A99 (2016)

[10] P. C. J. Ada Bibang, A. N. Agnihotri, B.Augé, P. Boduch, C. Desfrançois, A. Domaracka, F. Lecomte, B. Manil, R. Martinez, G.S.V. Muniz, N. Nieuwjaer, H. Rothard, Low Temp. Phys. 45, 692 (2019)

[11] A.-R. Soliman, A.M. Hamid, I. Attah, P.Momoh, M. Samy El-Shall, J. Am. Chem. Soc. 135, 155 (2013) 
[12] X. Y. Lv, A. L. F. de Barros, P. Boduch, V. Bordalo, E. F. da Silveira,

A. Domaracka, D. Fulvio, C. A. Hunniford, T. Langlinay, N. J. Mason,

R. W. McCullough, M. E. Palumbo, S. Pilling, H. Rothard, and G. Strazzulla, Astron. Astrophys. 546, A81 (2012)

[13] E. Seperuelo Duarte, P. Boduch, H. Rothard, T. Been, E. Dartois, L.S.Farenzena, E.F. da Silveira, Astron. Astrophys. 502, 599 (2009)

[14] B. M. McMurtry; A.M. Tumer, S.E.J. Saito, R.L. Laiser, Chem. Phys. 472, 173 (2016)

[15] E. Dartois, B. Augé, P. Boduch, R. Brunetto, M. Chabot, A. Domaracka, J. J. Ding, O. Kamalou, X. Y.Lv, H. Rothard, E. F. da Silveira, and J. C. Thomas, Astron. Astrophys. 576, A125 (2015)

[16] A.L.F. de Barros, P. Boduch, A. Domaracka, H. Rothard, and E.F. da Silveira, Low Temp. Phys. 38, 953 (2012)

[17] G.S. Vignoli Muniz, C. F. Mejía, R. Martinez, B. Augé, H. Rothard, A. Domaracka, P. Boduch, Astrobiology 17, 298 (2017)

[18] S. Pilling, E. Seperuelo Duarte, E. F. da Silveira, E. Balanzat, H. Rothard, A. Domaracka, and P. Boduch, Astron. Astrophys. 509, A87 (2010)

[19] G. S. Vignoli Muniz, Ph. D. thesis, Normandie Univ- UNICAEN, 2017 https://tel.archives-ouvertes.fr/tel-01647924/document

[20] SRIM - The Stopping and Range of Ions, edited by Matter J.F. Ziegler, J. P. Biersack, M. D. Ziegler (Chester 2008), www.srim.org (2008)

[21] E. Dartois, J. J. Ding, A.L.F. de Barros, P. Boduch, R. Brunetto, M. Chabot, A. Domaracka, M. Godard, X. Y. Lv, C. F. Mejía Guamán, T. Pino, H. Rothard, E. F. da Silveira, J. C. Thomas, Astron. Astrophys. 557, A97 (2013)

[22] N. L. Evans, C. J. Bennett, S. Ullrich, R.I. Kaiser, Astrophys. J. 730, 69 (2011)

[23] P. A. Gerakines, R. L. Hudson, M. H. Moore, J.-L. Bell, Icarus 220, 647 (2012)

[24] P.A. Gerakines, R.L. Hudson, Astrobiology 13, 647 (2013)

[25] C. K. Materese, P. A. Gerakines, R. L. Hudson, Astrobiology 20, 956 (2020)

[26] W. Portugal, S. Pilling, P. Boduch, H. Rothard, D. Andrade, Mon. Not. Roy. Astron. Soc. 441, 3209 (2014)

[27] C.A. P. da Costa, G.S. Vignoli Muniz, P. Boduch, H. Rothard, E. F. da Silveira, Int. J. Mol. Sci. 21, 1893 (2020)

[28] J. Bouwman, A.L Mattioda, H. Linnartz, L. J. Allamandola, Astron. Astrophys. 525, A93 (2011)

[29] P. Markush, P. Bolognesi, A. Cartoni, P. Rousseau, S. Maclot, R. Delaunay, 
A. Domaracka, J. Kocisek, M. C. Castrovilli, B. A. Huber, L. Avaldi, Phys. Chem.

Chem. Phys. 18, 16721 (2016)

[30] M. C. Castrovilli, P. Markus, P. Bolognesi, P. Rousseau, S. Maclot, A. Cartoni,

R. Delaunay, A. Domaracka, J. Kocisek, B. A. Huber, L. Avaldi, Phys. Chem. Chem. Phys. 19, 19807 (2017)

[31] R. Martinez, A.N. Agnihotri, Ph. Boduch, A. Domaracka, D. Fulvio, G. Muniz,

M.E. Palumbo, H. Rothard, G. Strazzulla, J. Phys. Chem. A 123, 8001 (2019)

[32] M. Carmen Sicilia, C. Muñoz-Caro, A Niño, ChemPhysChem 6, 139 (2005)

[33] N. Esteves-López, S. Coussan, C. Dedonder-Lardeux, C. Jouvet, Phys. Chem. Chem. Phys. 18, 25637 (2016)

[34] X; Pang, C; Jiang, W. Xie, W. Domcke, Phys. Chem. Chem. Phys. 21, 14073 (2019)

[35] Nanoscale Insights into Ion-Beam Cancer Therap, edited by Andrey Solov'yov, (Springer 2017)

[36] J. Thariat, S. Valable, C. Laurent, S. Haghdoost, E.A. Pérès, M. Bernaudin, F. Sichel, P. Lesueur, M. Césaire, E. Petit, A.E. Ferré, Y. Saintigny, S. Skog, M. Tudor, M. Gérard, S. Thureau, J.-L. Habrand, J. Balosso, F. Chevalier, Int. J. Mol. Sci. 21,133 (2020) 